\title{
Utilizing stored wind energy by hydro-pumped storage to provide frequency support at high levels of wind energy penetration
}

\author{
A. B. Attya \\ Wind Energy Research Center \\ University of Strathclyde \\ a.attya83@gmail.com
}

\author{
T. Hartkopf \\ Renewable Energies department \\ Technical University of Darmstadt
}

\begin{abstract}
Wind farms (WFs) contribution in frequency deviations curtailment is a grey area, especially when WFs replace large conventional generation capacities. This paper offers an algorithm to integrate hydro-pumped storage station (HPSS) to provide inertial and primary support, during frequency drops by utilizing stored wind energy. However, wind turbines follow maximum power tracking, and do not apply frequency support methods, thus the wasted wind energy is mitigated. Firstly, HPSS rated power and energy capacity are determined based on several givens, including wind speed and load characteristics. Thus, HPSS major aspects are estimated (e.g., pump(s), reservoir layout, and generator(s)). Secondly, offered algorithm coordinates energy storage, and releasing through several dynamic and static factors. HPSS output is continuously controlled through a timed approach to provide frequency support. A hypothetical system is inspired from Egyptian grid and real wind speed records at recommended locations to host WFs. Case studies examine the algorithm impact on frequency recovery, at $40 \%$ wind power penetration. The responses of thermal generation and HPSS are analysed to highlight the influence of tuning the parameters of the proposed algorithm. The assessment of several frequency metrics insures the positive role of HPSS in frequency drops curtailment. Simulation environments are MATLAB and Simulink.
\end{abstract}

Keywords- wind power, hydro-pumped storage, frequency drops

\section{Nomenclature}

$\begin{array}{ll}\text { AOP } & \text { Annual Occurrence Probability in percentage } \\ \mathrm{f}_{\mathrm{o}} & \text { Nominal system frequency } \\ \mathrm{G} & \text { Ratio from the pipe diameter to be opened } \\ h_{\min } & \text { minimum water head } \\ h_{r} & \text { maximum water head } \\ \Delta \mathrm{P} & \text { Power deviation between load and generation }\end{array}$


$\Delta \mathrm{P}_{\mathrm{ch}} \quad$ The power directed to run HPSS pumps

$\Delta \mathrm{P}_{\text {s-fixed }} \quad$ Fixed component of support power

$\mathrm{A}_{\mathrm{r}} \quad$ Reservoir area

CGC Conventional Generation Contribution

$\mathrm{D}_{\mathrm{d}} \quad$ Discharge pipe diameter

G-90 Gameza wind turbine $2 \mathrm{MW}$

GE-77 General Electric wind turbine 1.5 MW

$\mathrm{H} \quad$ Power system aggregate inertia

HPSS Hydro-Pumped Storage Station

$\mathrm{K}_{\text {pen }} \quad$ Wind power penetration factor

MPT Maximum Power Tracking

Q Flow rate: suffices ' in' and 'out' refer to flow rates to/from HPSS

$\mathrm{P} \quad$ Power running the pumps of HPSS

$\operatorname{RoCo} \Delta \mathrm{f} \quad$ Rate of change of frequency deviation

$\mathrm{R}_{\mathrm{WFs}} \quad$ Wind farms equivalent virtual droop

$\mathrm{S}_{\mathrm{b}} \quad$ Base apparent power (VA)

$\mathrm{T}_{c f} \quad$ Maximum allowed duration to completely fill the water reservoir

$\mathrm{T}_{\text {rated }} \quad$ Sustainable duration for HPSS rated power generation

$\mathrm{T}_{\text {safe }} \quad$ Duration before support stops after frequency event mitigation

$\mathrm{T}_{\mathrm{SM}} \quad$ Time required to reach safe margin for the first time after event initiation

$\mathrm{V}_{\mathrm{r}} \quad$ Reservoir volume

WF Wind Farm

WS Wind Speed

$\mathrm{WS}_{\mathrm{avg}} \quad$ Annual average wind speed in certain location

WT Wind Turbine

$\Delta \mathrm{f}_{\mathrm{m}} \quad$ Maximum frequency drop

$\Delta f_{\text {RMS }}, \Delta f_{\text {avg }}$ RMS and average values of frequency variations within 60 s from event initiation

\section{Introduction}

Wind integration in modern and conventional power systems is presently one of the most active research fields. Several risks are facing conventional energy generation, namely, depleted resources, high fossil fuels prices and pollutant emissions. However, most of renewable energies are still struggling against many obstacles, which avoid high penetration levels in conventional grids. Technically, wind energy high penetration levels imply negative impacts on system stability, especially during faults. Thus, research efforts are directed towards predicting and simulating system voltage and frequency attitudes, when wind energy 
replaces conventional units $[1,2,3]$. Supposedly, optimum results are achieved when WFs operate typically like conventional plants.

The next lines discuss the different methods offered in literature to enhance the role played by WFs in frequency deviations elimination. Most of proposed methods count on wind turbine (WT) over speeding and / or other de-loading techniques. As an illustration, running WT at higher rotational speed than its optimum value that is determined according to Maximum Power Tracking (MPT) [4], makes the rotating parts of WT store more kinetic energy. Thereupon, certain ratio from stored kinetic energy is extracted by decelerating WT speed to certain threshold $[5,6]$. The influence of WFs integration in conventional power systems on system inertia was studied in [7]. It concluded that the penetration of variable speed WT in power system does not affect its total inertia, if no conventional plants are displaced. On the other hand, WT de-loading can be applied using pitch angle control, so that WT output is reduced below its optimum value by setting the pitch angle to a higher value (i.e., pitch deloading). Consequently, the difference between optimum and de-loaded outputs acts as a backup to suppress any sudden deviation between load demand and generated power [8]. Nevertheless, the feasibility of such method depends on the accuracy and speed of pitch angle electrical and mechanical control, as well as on-spot wind speed (WS) measurements.

Through the previously discussed algorithms, WT operation deviates from MPT; hence some energy is wasted in the favour of providing acceptable support to grid at frequency drops. In addition, WFs contributions in drops curtailment are always ambiguous, as it strongly counts on WS conditions before, during and after the frequency drop [6]. For example, at high WSs, the system is supported for longer duration conversely; low WSs increase frequency fluctuations, and the probability of suffering a second drop. Furthermore, WT inertia and aerodynamics have a deep influence on WT participation in frequency recovery. Considering all these mentioned drawbacks, integrating energy storage methods to provide the required power support during frequency events seems to be preferable. It is of note that, the economical aspect is not the interest of this paper.

Literature presented several types of energy storage, namely, batteries banks, HPSS, hydrogen reservoirs and flywheels [9]. However, this paper integrates HPSS to provide controlled increase in generated active power during frequency events (i.e., inertial and primary responses). Three main topics should be discussed in this field, markedly, storage facility sizing, charge/discharge control, and then the expected impact on system frequency. The estimation of the required storage capacity is related to the available chronological WS at 
WFs' locations. Likewise, the limitations on capacity assessment are coherently related to the geographical nature of construction site of HPSS [10,11]. Number and ratings of installed pumps, as well as water reservoir volume determine the maximum amount of stored energy and rated power. In addition, filling and emptying durations of water reservoir(s) (i.e., which are equivalent to charging and discharging times of batteries [12]) have a major impact on frequency drops mitigation, especially, if the system suffered two consecutive drops within short period. The sizing of storage mediums is highlighted in literature, especially for battery banks; however, proposed algorithms could be applied on other storage mediums. In [13], a numerical methodology for optimum sizing of a reversible hydraulic system was offered. This storage facility was designed to recover WFs electric energy which is rejected due to grid limitations. Reject wind power means that a certain portion from $\mathrm{WFs}_{\mathrm{op}}$ is not fed to the system to maintain the minimum limit of conventional contribution. Practically, this is achieved through several methods, for example pitch de-loading for WTs outputs, or accelerating WTs (i.e., as long as their speed limits are not violated). In some extreme cases when excess power is high for long periods (e.g., during late night hours when the demand is relatively low while the wind is blowing well) some WTs are stopped to reduce the WFs output. However, this sizing procedure was based on economical aspects, and it did not consider system requirements during peak load intervals. Moreover, the storage station did not provide power support during frequency deviations instead of the integrated WFs.

In general, the mentioned literature utilized energy storage as a solution for the negative influence of the intermittent nature of WFs output. But there was no solid trial to exploit storage mediums, namely, HPPS stations, as a backup source for energy in case of frequency excursions to provide positive support in analogy to conventional plants. Therefore, the presented research aims two targets, firstly, estimating the required storage capacity, and the rated power of storage facility in the light of its intended role. Although, the authors have already discussed this part in [14], a brief description is provided in this paper to achieve coherency. The second target is proposing a novel Normal-Support operation algorithm for HPSS that guides wind energy storage, and contribution in frequency drops mitigation. This algorithm utilizes HPSS to compensate the negative impact of conventional generation retirement (i.e., replaced by WFs). In addition, WTs are operated using MPT method instead of applying special support algorithms, hence wasted wind energy is alleviated. The paper also investigates the dependence of support algorithm parameters on the specifications of HPSS. An example for the proposed significant schemes is the implementation of a dual-component supportive active power provided by HPSS during frequency events. This supportive power is 
also linked to WFs penetration level, through the theoretical concept of frequency droop. The offered algorithm could be applied on any grid in cooperation with group of WFs, such that it does not require special operation algorithms for WTs and it provides predetermined levels of power support during frequency events. The implied test system emulates a medium sized power system inspired from the Egyptian power system generation and WSs data.

This paper is composed from six sections including this introduction. Next section summarizes the essential data about the imitated sector from the Egyptian system, and wind energy integration. Third section explains briefly the proposed sizing algorithm of HPSS, and then it is applied on the considered test system. The proposed Normal-Support operation algorithm is explained in Section four. Results are discussed in the fifth section, meanwhile Section six concludes.

\section{The implemented test system}

\subsection{Power system and wind energy prospects}

The implemented test system is a hypothetical system that provides an initial indication about an electrical-geographical sector from the Egyptian Power System (nominal frequency $\left(\mathrm{f}_{\mathrm{o}}\right.$ ), and total generation capacity are $50 \mathrm{~Hz}$ and $19.7 \mathrm{GW}$ respectively according to the governmental report in 2010). It is of note that, this research work is partially funded by the Egyptian ministry of scientific research, that's why the test system is inspired from the Egyptian case. In particular, this paper does not aim to assess the 'actual' Egyptian System, but it implements some data about the Egyptian case (e.g. WS conditions and the load-generation characteristics). The actual present ratio between generation capacity and load demand slightly deviates from the applied ratio. In words, the authors have a great potential to apply real data instead of examining the proposed algorithms on a completely hypothetical system with artificial WS chronological data.

The encircled conventional plants shown in Figure 1 form an islanded hypothetical power system in the investigated case study. The paper examines the case of high WFs penetration replacing conventional plants, and this is easier to achieve in this relatively smaller trimmed sector. In addition, this islanded system has a lower inertia compared to the whole Egyptian Power System (i.e., it has lower generation capacity leading to a 'weaker' system), hence the impact of frequency deviations is severer and the positive participation of HPSS is emphasized. 
The participation of the excluded part in frequency recovery will definitely improve frequency response, and reduces penetration level of WFs in generation capacity (i.e., conventional generation capacity will increase).

This sector is selected due to the concentration of seven candidate WFs shown in Figure 1 (presently, none of these WFs are constructed), whose locations have promising WS conditions and appropriate topography. The available WS data in each location are average WSs records every 10 minutes. The conventional generation capacity before wind energy integration is 2400 MW as revealed by Table 1 [15].

The seven WFs will replace certain portion from the system initial conventional capacity based on their capacity factors. Generally, the actual capacity of a WF counts on several parameters including WF area, number of WTs per WF, types of installed WTs in WF and the implemented operation criteria. However, accurate estimation for wind energy capacity factor could not be achieved due to WS fluctuating nature. The actual capacity based on probabilistic and chronological estimations was in range of 25 to $45 \%$ [16]. Meanwhile, according to practical estimation in relevance to WSs records and WFs specifications in certain region, the actual capacity reached 55\% [17]. Thus, it is assumed that the integrated WFs actual capacity is $50 \%$ from their rated powers to determine the shut-down conventional generation capacity. Applying a relatively high capacity factor is an additional challenge to the proposed algorithm. In particular, the retired conventional capacity is higher (i.e., higher wind energy penetration), hence the test system is more affected and the role of the HPSS is emphasized.

Two types of WTs are integrated in each WF, namely, General Electric-1.5 MW (GE-77) and Gameza-2 MW (G-90). The MPT performance curves of both types are implemented to estimate each WT output at different WSs as explained later in Section 4 [18,19]. Integrated WFs are configured to replace $40 \%$ from the conventional generation, so that the two types of WTs have equal share in wind generation rated capacity. WFs penetration in generation capacity is $40 \%$ from $2400 \mathrm{MW}=960 \mathrm{MW}$, thus WFs rated capacity $=960 / 50 \%$ (the assumed capacity factor $)=1920 \mathrm{MW}$, hence the total numbers of installed GE-77 and G-90 are 640 and 480 WTs respectively. The number of WTs in each location depends on its $\mathrm{WS}_{\text {avg }}$ using simple proportional ratio (e.g., No. of GE-77 in Nabq $=\left[\left(W S_{\text {avg }} \cdot\right.\right.$ Total number of GE-77 WTs $) /\left(\sum\right.$ $\left(W S_{\text {avg }}\right.$ in all sites)]). The annual average WSs $\left(\mathrm{WS}_{\mathrm{avg}}\right)[20]$, and the no. of WTs from each type in each WF are found in Table 2. 
Table 1 Conventional generation in considered zone

\begin{tabular}{|c|c|c|c|}
\hline No. & Plant & Type & Capacity \\
\hline 1 & Gulf of Suez I and II & Steam & $668 \mathrm{MW}$ \\
\hline 2 & Ataka & Steam & $900 \mathrm{MW}$ \\
\hline 3 & Auon Mousa & Steam & $640 \mathrm{MW}$ \\
\hline 4 & Sharm Elsheikh & Gas & $192 \mathrm{MW}$ \\
\hline
\end{tabular}

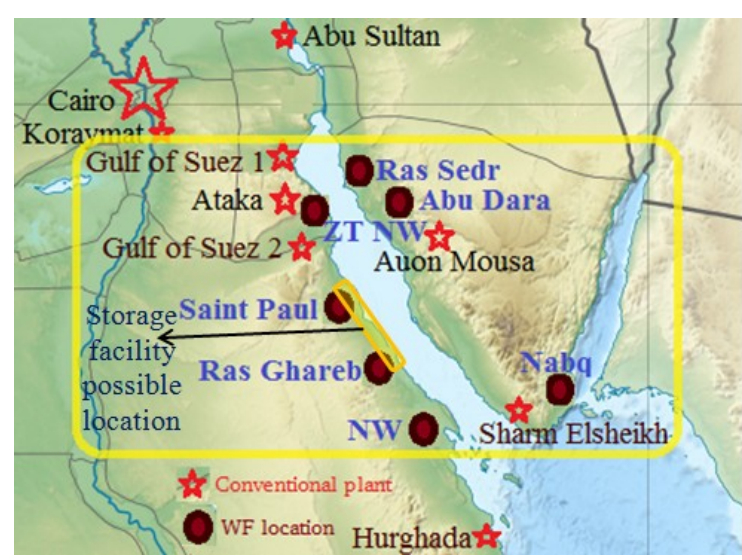

Fig. 1 The assumed hypothetical zone and WFs

Table 2 Annual average WSs in WFs locations (WSavg, $\mathrm{m} / \mathrm{s}$ ), and number of installed WTs

\begin{tabular}{|c|c|c|c|c|}
\hline No. & WF & WS $_{\text {avg }}$ & No. of GE-77 & No. of G-90 \\
\hline 1 & Nweiba & 10 & 106 & 74 \\
\hline 2 & ZT & 10 & 106 & 74 \\
\hline 3 & Ghareb & 9.8 & 104 & 73 \\
\hline 4 & Paul & 8.25 & 87 & 61 \\
\hline 5 & Dara & 8.21 & 87 & 61 \\
\hline 6 & Ras Sedr & 7.4 & 78 & 55 \\
\hline 7 & Nabq & 6.85 & 72 & 51 \\
\hline
\end{tabular}

The Egyptian grid chronological hourly load in 2010 is integrated after it is reduced by $87.8 \%$ (i.e., ratio between the concerned sector generation capacity to the complete capacity $=$ $2400 / 19700=12.2 \%$ ). The main aim of this assumption is to apply a real annual loading curve instead of an artificial one; mainly to it investigate the correlation between WS conditions and load demand variations. In addition, the details of transmission and distribution voltage levels are not of high interest for the proposed research work. Generally, the diversity in loading pattern slightly affects the results of HPSS sizing, which is not the main concern of this paper.

\subsection{Structure of integrated storage facility}

\subsubsection{Water resource and storage reservoir}

Proposed case study assumes that HPSS is constructed near by the Red sea as indicated in Figure 1. The suggested approximate location relies on the basic available geographical data about the nature of the terrain between some hills there, and the Red Sea (e.g. the height of hills, and the distance between sea effective zone to provide water and the foot of the hills). The cross sectional area of pipe(s) delivering water to the reservoir, discharge pipe diameter 
$\left(D_{d}\right)$, storage reservoir height, volume $\left(V_{r}\right)$, and the rectangular bottom area $\left(A_{r}\right)$ are determined through the sizing algorithm offered in the next section.

\subsubsection{Pumps}

The pumps are responsible for lifting the water from datum level to storage reservoir. The number and ratings of pumps count on the expected input power from WFs excess generation (i.e., rejected wind power), as explained in the next section. In addition, the target time to completely fill the reservoir is considered. Other factors related to pump operation, for example, efficiency $(\eta)$ and flow rate $(Q$ with suffices 'in' and 'out' refer to input and output flow rates to/from HPSS) at certain heights and input powers are stated by pumps' vendors in the form of performance curves [21]. The dominant type of pumps in hydro storage projects is mixed flow, and in some cases radial pumps.

The comparison between the integration of multiple turbines and pumps versus single pump/turbine technology is an interesting topic. However, this paper focuses on the role of HPSS in frequency drops mitigation, especially when WFs replace conventional power plants. In addition, most of the constructed HPSS are equipped with conventional pump(s) and turbine(s), because pump/turbine solution requires further development and investigations to reach acceptable levels of reliability, availability, maintainability, and safety [22]. The same point of view applies for the aspect of 'generator/pump motor'.

\subsubsection{Generation plant}

Certain number of hydro generators represents the generation plant responsible for supplying electrical power to the grid. The number of generators depends on the total rating of the storage facility and the available budget to purchase, run and maintain the integrated generator(s). As long as the amount of stored water is sufficient, hydro turbine(s) provides mechanical power to run generator shaft, hence electrical energy is available.

\section{Sizing of rated power and energy capacity}

The contents of this section are widely discussed in an independent paper [14]. However, a brief illustration is presented in this section.

\subsection{Proposed algorithm}

Annual chronological data of WSs and load demand are prerequisites for executing the following procedure. In addition, the numbers and the specifications of WTs inside the connected WFs and their capacity factors should be predetermined. 
a. Obtain the annual generation arrays of integrated WFs. To perform this task, the WSs arrays incident on each WT inside the WF are processed through the MPT performance curves of integrated WTs types in each WF. The transient variations in output power that occurs due to the transition from one WS to another are ignored to facilitate the calculations. Moreover, these transients have a very minor influence on the final results. According to the available WS data and for simplicity, WF is aggregated as a single WT representing each type of installed WTs. The rating of this single WT is the product of installed WTs' rating and number of the same type (i.e., in the presented case each WF is aggregated by two large WTs).

b. Annual load demand chronological array should have the same time resolution of WFs output power arrays (e.g., if the WS is recorded every 10 minutes then the load demand value is defined in the same time step).

c. The preferred conventional generation contribution (CGC) in load feeding is adjusted to certain value, which is not very high to avoid the rejection of high amounts of wind energy. In this paper, it is assumed that CGC is $70 \%$ (i.e., $70 \%$ from the load is fed by conventional plants and $30 \%$ by WFs, if WFs' output ( $\mathrm{WFs}_{\mathrm{op}}$ ) is sufficient to achieve this condition).

d. The annual array of net generation (conventional and wind) is subtracted from annual load demand array to obtain $\Delta \mathrm{P}$ array (i.e., positive values of $\Delta \mathrm{P}$ refer to excess wind power, while negative values refer to power shortage events).

e. Finally, values of $\Delta \mathrm{P}$ array are classified into different ranges and the annual occurrence probability (AOP) of each range is calculated. In particular, positive $\Delta \mathrm{P}$ gives a good indication for the average excess $\mathrm{WFs}_{\mathrm{op}}$ that is utilized to run the pump(s), thus rated power of installed pumps is roughly determined. On the other hand, negative $\Delta \mathrm{P}$ refers to the required power generation from HPSS either to mitigate frequency drops, or to reduce $\mathrm{WFs}_{\mathrm{op}}$ fluctuations. Final values of positive and negative $\Delta \mathrm{P}$ should be compromised with the available budget, and geographical aspects to determine the number of pumps, maximum water head $\left(h_{r}\right)$, reservoir bottom elevation from the ground (i.e., water minimum head $\left(h_{\text {min }}\right)$ ), and the specifications of installed generator(s).

\subsection{Application on the implemented test system}

The assessment of $\mathrm{WFs}_{\mathrm{op}}$ reveal that the highest monthly average, namely, $1465 \mathrm{MW}$ is achieved in January, meanwhile the lowest monthly average (662 MW) occurred in August. AOP of several positive and negative $\Delta \mathrm{P}$ ranges are summarized in Table 3 . The dominant positive $\Delta \mathrm{P}$ with a reasonable value is in range of 200 up to $400 \mathrm{MW}$ ( $\mathrm{AOP}=7.3 \%$ ). On the other hand, the most frequent negative $\Delta \mathrm{P}$ is in range of 200 up to $300 \mathrm{MW}$ with $3.3 \%$ AOP. The arising question is; what happens at higher values of negative $\Delta \mathrm{P}$ ? First of all, sever 
deviations are reduced by increasing conventional generation loading to $95 \%$, as high load demand force the raising of CGC. On the other side, increasing HPSS generator rating is a two sided blade, when the HPSS energy capacity (volume of stored water) is not increased in correspondence. As an illustration, increasing the generator output will shrink the available support time span because the stored energy is depleted faster. Additionally, it is impractical and non economic to consider very high negative $\Delta \mathrm{P}$ events whose occurrence probabilities are very minor. Based on the previous discussion, the rated power of HPSS is selected to be 300 MW and Qout is obtained using (1), where $\rho$ and $g$ are the water density, and earth gravity respectively. Taking into consideration comparable executed projects, and the terrain nature of the considered construction area; $h_{r}$ and $h_{\min }$ are assumed to be 80 and $60 \mathrm{~m}$ respectively.

Table 3 ranges of negative and positive $\Delta \mathrm{P}$ (in MW) and their annual occurrence rates

\begin{tabular}{|c|c|c|c|}
\hline Negative $\Delta \mathbf{P}$ & AOP & Positive $\Delta \mathbf{P}$ & AOP \\
\hline $700 \leq \Delta \mathrm{P}<800$ & $0.6 \%$ & $1200 \leq \Delta \mathrm{P}<1400$ & $11.1 \%$ \\
\hline $600 \leq \Delta \mathrm{P}<700$ & $0.8 \%$ & $1000 \leq \Delta \mathrm{P}<1200$ & $17.5 \%$ \\
\hline $500 \leq \Delta \mathrm{P}<600$ & $1.1 \%$ & $800 \leq \Delta \mathrm{P}<1000$ & $15.1 \%$ \\
\hline $400 \leq \Delta \mathrm{P}<500$ & $1.4 \%$ & $600 \leq \Delta \mathrm{P}<800$ & $11.5 \%$ \\
\hline $300 \leq \Delta \mathrm{P}<400$ & $2.2 \%$ & $400 \leq \Delta \mathrm{P}<600$ & $8.2 \%$ \\
\hline $200 \leq \Delta \mathrm{P}<300$ & $3.3 \%$ & $200 \leq \Delta \mathrm{P}<400$ & $7.3 \%$ \\
\hline
\end{tabular}

The HPSS rated power generation should sustain for certain duration $\left(\mathrm{T}_{\text {rated }}\right)$ which decides the energy capacity and the water reservoir volume. It is assumed that $T_{\text {rated }}$ is half an hour when the water reservoir is initially full. According to obtained results, Q Qut $=382 \mathrm{~m}^{3} / \mathrm{s}, \mathrm{V}_{\mathrm{r}}$ is $687600 \mathrm{~m}^{3}$, and $\mathrm{A}_{\mathrm{r}}$ is $34380 \mathrm{~m}^{2}$.

$$
\Delta P_{\text {negative }}=\rho \cdot g \cdot h_{r} \cdot Q_{\text {out }}
$$

In this research work, a pump fabricated by Voith Company is implemented [23]. The major specifications of the pumping station are found in Table 4. The number and rating of pumps are based on the selected positive $\Delta \mathrm{P}$. Moreover, the maximum allowed duration to completely fill the water reservoir $\left(\mathrm{T}_{c f}\right)$ is a prerequisite to identify the integrated pump(s) characteristics. As an illustration, aggregated discharge rates of the installed pumps should fill the reservoir starting from $h_{\min }$ to reach $h_{r}$ within no longer than $\mathrm{T}_{c f}\left(\mathrm{~T}_{c f}\right.$ is 4 hours in this paper as the reservoir is relatively small). $Q_{\text {in }}$ of each pump is estimated using (2); where $S_{g}$ is water specific gravity, $\eta$ is the pump efficiency and $\mathrm{P}$ is the available power in $\mathrm{kW}$. For enhanced simulation accuracy, $\eta$ is also dynamic based on instantaneous water level $(h)$. As an illustration, according to the curves of the integrated pump, $\eta$ is 69 and $78 \%$ at $h_{r}$ and $h_{\text {min }}$ respectively. For simplicity, $\eta$ is decaying linearly when $h$ increases using (3), which is derived based on the two mentioned operation points. $D_{d}$ is selected to achieve the required $Q_{\text {out }}$ to 
generate the rated plant output (i.e., at $\mathrm{G}=1$ where $\mathrm{G}$ is the gate opened ratio from the whole pipe diameter $\left(\mathrm{D}_{\mathrm{d}}\right)$ ) using (4). According to the pump curves, and at $h_{r}$, the nominal pumping rate of a single pump is $22.5 \mathrm{~m}^{3} / \mathrm{s}$ [14]. Thus, the aggregate pumping rate of all the pumps is $5 \cdot 22.5 \mathrm{~m}^{3} / \mathrm{s}=112.5 \mathrm{~m}^{3} / \mathrm{s}$, thus the reservoir is filled after about 1.7 hours.

$$
\begin{aligned}
& Q_{\text {in }}=\frac{0.102 \cdot P \cdot \eta(h)}{W_{L} \cdot S_{g}} \\
& \eta=-0.0055 \cdot h+1.12 \quad\left(h_{\min } \leq h \leq h_{r}\right) \\
& Q_{\text {out }}=0.25 \cdot \pi \cdot G \cdot D_{d}^{2} \sqrt{2 \cdot g \cdot h}
\end{aligned}
$$

Finally, power generation takes place through one propeller turbine driving a synchronous generator of $300 \mathrm{MW}$ rated power. The generator acts as running reserve to eliminate synchronization time and suppress transients [24]. It is worth mentioning that, power plant primary response for frequency deviations is mainly affected by the droops and ratings of the installed generators which decide the increase in output power to mitigate the frequency drop. Thus, using one aggregate generator or multiple parallel generators (having the same equivalent rated power, identical droops and governors) is almost similar. Likewise, the power system inertia is aggregated in one transfer function [25], hence using several generators or one equivalent large generator causes marginal difference. From simulation point of view, using one aggregate generator reduces the computational efforts and simulation time, and does not imply any deviation in results, when it is compared to parallel generators having an equivalent summative rating, and identical parameters. Generally, from reliability point of view, installing more than one generator instead of one aggregate unit might be preferred. The major components of the integrated HPSS are depicted in Figure 2. It is of note that the model of the applied standard governor is found in [26], and its figure is depicted in the Appendix. 


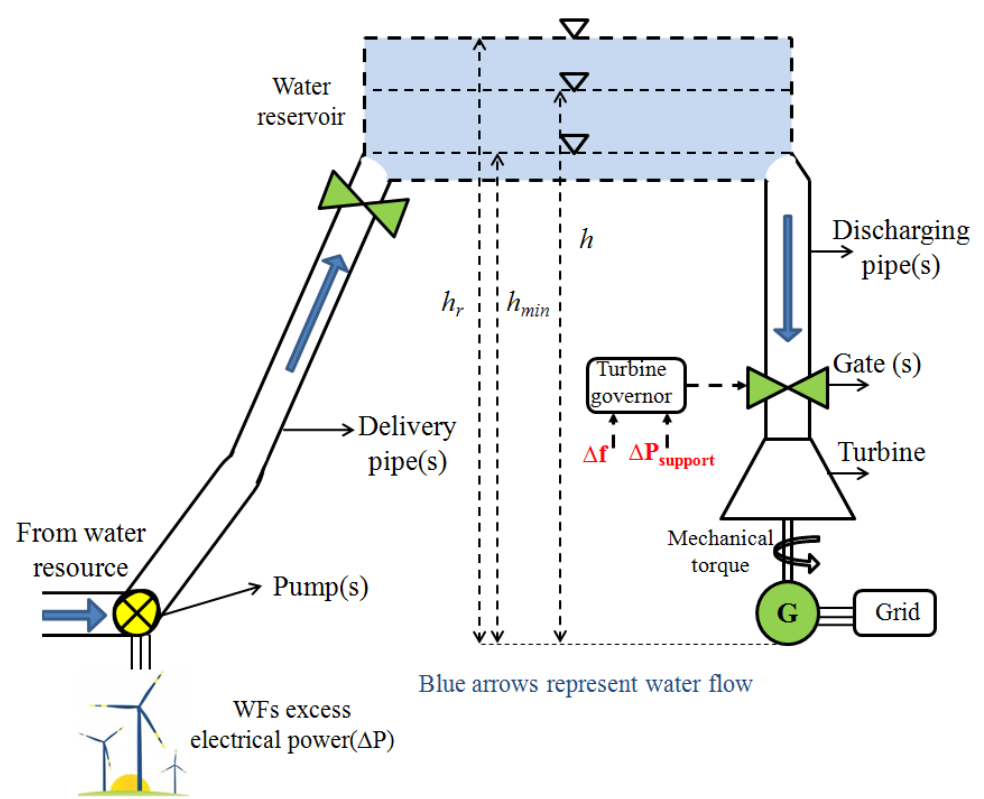

Fig. 2 HPSS major components and layout

Table 4 Integrated pumping station specifications

\begin{tabular}{|c|c|}
\hline Type & Radial flow \\
\hline Input power rating & $20 \mathrm{MW}$ \\
\hline Rated discharge rate at $h_{r}$ & $22.5 \mathrm{~m}^{3} / \mathrm{s}$ \\
\hline Efficiency at ' $h_{\min }$ ' & $78 \%$ \\
\hline Runner diameter & $3.5 \mathrm{~m}$ \\
\hline No. of pumps & 5 \\
\hline Inlet pipe diameter & $3.8 \mathrm{~m}$ \\
\hline Discharge pipe diameter & $3.5 \mathrm{~m}$ \\
\hline
\end{tabular}

\section{Operation algorithm}

Proposed algorithm monitors four variables, namely, load demand, $\mathrm{WFs}_{\mathrm{op}}, h$ and frequency deviation $(\Delta \mathrm{f})$. The next two subsections explain the different combinations between the possible values of these variables and the corresponding decisions.

\subsection{Normal operation}

Normal operation refers to normal conditions of $\Delta \mathrm{f}$, markedly $\Delta \mathrm{f} \geq-0.05 \mathrm{~Hz}$ [27]. This operation mode decides whether there is excess wind energy to store or not, and insures that water level is within allowed limits. The energy storage (i.e., pumping water, or 'charging' in analogy to batteries) conditions are as the following:

$h<h_{r}$ and $W F s_{o p}>($ Load - conventional generation based on CGC)

Keep in mind that, $\mathrm{CGC}$ is adjusted to $70 \%$ as indicted in the previous section. In this case, the amount of excess $\mathrm{WFs}_{\mathrm{op}}$ above the indicated limit for conventional generation will run the 
pumps. This excess power is denoted by ' $\Delta \mathrm{P}_{\text {ch }}$ ', where the suffix ' $c h$ ' is referring to 'charging'. However, $\Delta \mathrm{P}_{\mathrm{ch}}$ must be sufficient to run at least one pump at the required water elevation level.

Since machines and equipments need time to respond based on the two previous conditions, thus, it is non-practical to check charging conditions instantaneously, but they are tested every certain fixed time frame. This time frame could be determined according to the implemented forecasting period of WS or $\mathrm{WFs}_{\mathrm{op}}$. For example, in this paper, WS chronological records are available every ten minutes, hence charging conditions are examined every time the WS changes (10 minutes). In reality, WSs do not change in all WFs in such synchronized manner; however, an average for all $\mathrm{WFs}_{\mathrm{op}}$ could be used at the beginning of time frame. It is of note that, the implemented synchronized WSs variations affect only the charging attitude, but it has no impact on HPSS contribution during frequency deviations.

Intensive simulation trials proved that the initiation of charging process must be regulated to avoid sudden unbalance in generation-demand. Thus, the dispersion of a portion from the $\mathrm{WFs}_{\mathrm{op}}$ (when the two above conditions are satisfied) to feed pumps is done gradually by a certain rate. This rate is adjusted based on the maximum possible dispersed power, namely, the aggregate rating of pumps. In particular, the withholding power increases by $1.67 \mathrm{MW} / \mathrm{s}$ (i.e., one minute is required to disperse power to run all pumps at their rated operation).

Power electronics devices are also responsible for keeping $\Delta \mathrm{P}_{\mathrm{ch}}$ within the limits of pumps' aggregate rating (as long as the $\mathrm{WFs}_{\text {op }}$ excess output is sufficient). However, when the WFs excess output exceeds pumps' demands, the difference is directed to feed the load and CGC is reduced to maintain generation-demand balance. System operators always set a maximum contribution limit for $\mathrm{WFs}_{\mathrm{op}}$ in generation mix (50\% in this paper). In particular, this occurs when $\mathrm{WFs}_{\mathrm{op}}$ is high and demand is low, so that WFs maximum contribution limit is violated, and then certain share from $\mathrm{WFs}_{\mathrm{op}}$ (i.e., $\mathrm{WFs}_{\mathrm{op}}-\Delta \mathrm{P}_{\mathrm{ch}}-50 \%$ Load) is wasted (i.e., rejected).

The implemented simulation model calculates dynamic $\mathrm{Q}_{\text {in }}$ using (2) and (3) such that $\mathrm{P}$ equals the share of each pump from $\Delta \mathrm{P}_{\mathrm{ch}}$ in $\mathrm{kW}$. At this point, a significant question arises concerning the pumps operation criteria: is it better to operate all the pumps in parallel, even if, at de-rated input power (i.e., divide $\Delta \mathrm{P}_{\mathrm{ch}}$ among the integrated pumps) or run certain number of pumps at their rated power according to $\Delta \mathrm{P}_{\text {ch }}$ ? Answering this question precisely needs an independent research, but this paper considered that $\Delta \mathrm{P}_{\mathrm{ch}}$ is equally divided between connected pumps, so that the pumps run in a synchronized manner with the same loading ratio. The aggregate input flow rate to the reservoir is obtained by algebraic summation for the discharge rates of all pumps, because they are connected in parallel. 


\subsection{Support operation}

This mode is responsible for providing appropriate power support $\left(\Delta \mathrm{P}_{\mathrm{s}}\right)$ during moderate frequency deviations (i.e., $\Delta \mathrm{f}<-0.05 \mathrm{~Hz}$ ). $\Delta \mathrm{P}_{\mathrm{s}}$ is generated by HPSS, and evaluated using (5). As an illustration, $\Delta \mathrm{P}_{\mathrm{s}}$ has two components; fixed ( $\left.\Delta \mathrm{P}_{\mathrm{s} \text {-fixed }}\right)$ representing the reference power signal to the hydro unit, and the other is varying based on $\Delta \mathrm{f}$ severity. The fixed support signal is provided as the reference power signal to the gate of HPSS (acknowledging the limitations of opening rates and limits), while speed controller is responsible for the mitigation of frequency deviations based on the droop function (i.e., setting minor deviations in gate opening to provide $\left.\Delta \mathrm{P}_{\mathrm{s}}(\Delta \mathrm{f})\right)$. The value of $\Delta \mathrm{P}_{\mathrm{s} \text {-fixed }}$ is predetermined and adjusted according to several factors including the rating of HPSS, history of frequency deviations in concerned system, level of WFs penetration, and the expected support duration. Proposed algorithm evaluates $\Delta \mathrm{P}_{\mathrm{s}-}$ fixed in per unit through two different methods. The first one sets a predetermined value for $\Delta \mathrm{P}_{\mathrm{s}-}$ fixed based on WFs aggregated rating at certain moderate reference frequency drop (in this research; $\Delta f_{R}=0.3 \mathrm{~Hz}$ ) using (6). This equation reflects that, HPSS carries on the role which WFs should play in response to frequency drops. Keep in mind that WFs replaced some conventional units, so WFs contribution in frequency drops mitigation is carried out by HPSS. In particular, WFs should react as a conventional generator through certain droop $\left(\mathrm{R}_{\mathrm{WFs}}\right)$ whose default value is between 5 to $12 \%$ (i.e., $5 \%$ droop means that $5 \%$ deviation in frequency causes $100 \%$ change in generator pre-fault output) $[24,25]$. It is obvious that increasing $\Delta f_{R}$ puts higher burden on HPSS, hence $\Delta \mathrm{P}_{\text {s-fixed }}$ increases. Conversely, setting WFs' droop reduces the contribution of HPSS in frequency event mitigation (i.e., in analogy to conventional units). This method is considered to be simple and independent from the nature of each frequency event but it affects the smoothness of the frequency response, as $\Delta \mathrm{P}_{\mathrm{s}-\mathrm{fixed}}$ has a fixed value.

$$
\begin{aligned}
& \Delta P_{s}=\Delta P_{s-f i x e d}+\Delta P_{s}(\Delta f) \\
& \Delta P_{s-\text { fixed }}=\frac{\Delta f_{R}}{f_{o} \cdot R_{W F s}} \cdot \frac{W F s \text { aggregated rating }}{\text { HPSS rated power }}
\end{aligned}
$$

The second method of setting $\Delta \mathrm{P}_{\text {s-fixed }}$ is more complicated, and it counts on the nature of frequency drop. As an illustration, $\Delta \mathrm{P}_{\text {s-fixed }}$ is adjusted based on the rate of change of frequency deviation $(\operatorname{RoCo} \Delta \mathrm{f}$ in $\mathrm{Hz} / \mathrm{s})$ at the early stage of the drop. $\mathrm{RoCo} \Delta \mathrm{f}$ is evaluated within $0.5 \mathrm{~s}$ before frequency drop violates the safe margin, and then $\Delta \mathrm{P}_{\text {s-fixed }}$ is calculated using (7), where $\mathrm{K}_{\mathrm{pen}}$ stands for penetration factor in generation capacity and $\mathrm{S}_{\mathrm{b}}$ is the base apparent power of the investigated system. For example, in the examined case (explained in Subsection 2.1); $\mathrm{K}_{\text {pen }}$ $=920 /(2400-920)=0.62$. The dependency of $\Delta \mathrm{P}_{\mathrm{s}-\mathrm{fixed}}$ on $\mathrm{RoCo} \Delta \mathrm{f}$ is derived from frequency decay equation presented in Subsection 11.1 in [25]. The main concept is to make the 
frequency deviation curve, in its early risky stage, follow the same pattern of a corresponding (former) conventional system (i.e., before WFs integration and conventional units retirement). In particular, RoCo $\Delta \mathrm{f}$ gives an indication about the load-generation mismatch that caused the frequency drop. The WFs should contribute in mitigating this mismatch, so that the frequency drop is also mitigated, but the HPSS is integrated to carry out this role instead of WFs through the stored wind energy. Thus, a share from this mismatch is compensated by HPSS output that is mainly determined by $\Delta \mathrm{P}_{\mathrm{s} \text {-fixed. }}$ The share value depends on wind power penetration in generation capacity not on contribution in load feed (as load is varying all the time). This procedure is activated only when frequency violates the safe margin, otherwise $\operatorname{RoCo} \Delta \mathrm{f}$ signal is set to zero, so that $\Delta \mathrm{P}_{\text {s-fixed }}$ equals zero (i.e., no support; normal operation). It is of note that, $\Delta \mathrm{P}_{\mathrm{s} \text {-fixed }}$ is fixed for each frequency event, therefore, it is calculated at a single value for $\operatorname{RoCo} \Delta \mathrm{f}$, namely at the instant of violating the frequency safe margin.

$$
\begin{aligned}
& \Delta P_{s-f \text { ixed }}=\left(2 \cdot H_{o} \cdot \operatorname{RoCo\Delta } f_{\text {at drop initiaion in pu }}\right) \cdot K_{p e n} \cdot S_{b} \cdot \frac{1}{H P S S \text { rated capacity }} \\
& K_{p e n}=\frac{\text { WFs actual capacity }}{\text { Conventional generation capacity after WFs integration }}
\end{aligned}
$$

The variation of $\Delta \mathrm{P}_{\text {s-fixed }}$ with respect to system aggregate inertia and $\mathrm{K}_{\text {pen }}$ is displayed through a 3D graph in Figure 3. As expected, as $\mathrm{K}_{\text {pen }}$ increases HPSS must provide higher response, likewise deeper deviations excite higher fixed support. However, the penetration level has higher impact compared to deviation severity.

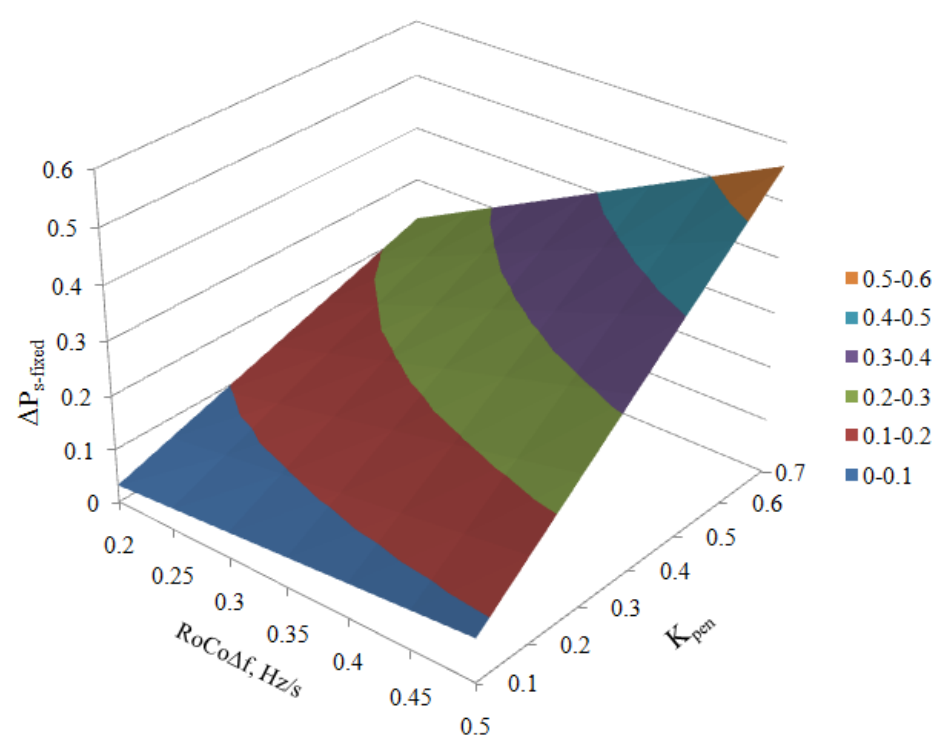

Fig. 3 Requested HPSS fixed support at different events $\left(H=5 \mathrm{~s}\right.$ and $\left.\mathrm{f}_{\mathrm{o}}=50 \mathrm{~Hz}\right)$

When $\Delta \mathrm{f}$ reaches the safe margin, $\Delta \mathrm{P}_{\mathrm{s}}$ continues for a certain fixed predetermined duration $\left(\mathrm{T}_{\text {safe }}\right) . \Delta \mathrm{P}_{\text {s-fixed }}$ and $\mathrm{T}_{\text {safe }}$ are inversely proportional and the constant of proportionality is the time inertia of HPSS (i.e., $\mathrm{T}_{\text {safe }}=\mathrm{H}_{\mathrm{HPSS}} / \Delta \mathrm{P}_{\text {s-fixed }}$ ). This constrain insures that frequency 
relatively stabilized within safe margin, before switching back to Normal operation. In addition, the sudden removal of $\Delta \mathrm{P}_{\mathrm{s} \text {-fixed, }}$ as soon as $\Delta \mathrm{f}$ hits the safe margin, for the first time, might cause a second drop. Another time constrain is applied on the signal, that informs the controllers of conventional generation with the instantaneous generation of HPSS $\left(\mathrm{T}_{\text {safe } 2}\right)$. $\mathrm{T}_{\text {safe2 }}$ insures the rapid response of conventional generation to frequency deviation in its early stage; independent from HPSS supportive act, thus the system primary response is improved. After $\mathrm{T}_{\text {safe }}$ ends, $\Delta \mathrm{P}_{\mathrm{s} \text {-fixed }}$ does not drop to zero instantly, but it decays uniformly $(0.01 \mathrm{p} . \mathrm{u} . / \mathrm{s})$ to guarantee a smooth post-fault frequency response. However, when stored potential energy runs out (i.e., $h=h_{\min }$ ) the support process halts. Intensive simulation experiments deduced that $\mathrm{T}_{\text {safe2 }}$ equals $30 \%$ from $\mathrm{T}_{\text {safe. }}$. Complete $\mathrm{WFs}_{\mathrm{op}}$ feed the load during support operation to curtail the frequency drop. Consequently, energy storage stops, even if the required conditions are satisfied, and storage is allowed only after 3 minutes from the continuous presence of frequency in safe margin. It is of note that, the maximum contribution limit of $\mathrm{WFs}_{\mathrm{op}}$ in generation mix is not violated under any circumstances. Figure 4 represents a compact flow chart for the major stages of Normal and Support operation modes.

The applied HPSS model is composed of two sub-models; one is simulating the hydro power plant and the other is simulating the water level attitude and pumps' performance. When HPSS is generating, the governor determines the required gate opening $(\mathrm{G})$. For simplicity, this is directly reflected on the opened ratio of $\mathrm{D}_{\mathrm{d}}$, hence $\mathrm{Q}_{\text {out }}$ is guided by $\mathrm{G}$ value as a ratio (i.e., as the output power increases $\mathrm{G}$ increases, thus $\mathrm{Q}_{\text {out }}$ increases. For simplicity G equals the HPSS output in p.u.

The proposed algorithm is simply applied to power systems. In particular, system operators will obligate WFs to provide frequency support, at high penetration levels of wind energy, based on certain requirements. The control signals are transmitted exactly as primary response, and other control signals are transmitted from control centres to generation units in present power systems. Thus, system operator role is to preset some parameters (e.g. method of $\Delta \mathrm{P}_{\text {s-fixed }}$ adjustment; $\mathrm{WFs}_{\mathrm{op}}$ contribution limits, safety durations, and frequency safe margin), but during events everything is automated. 


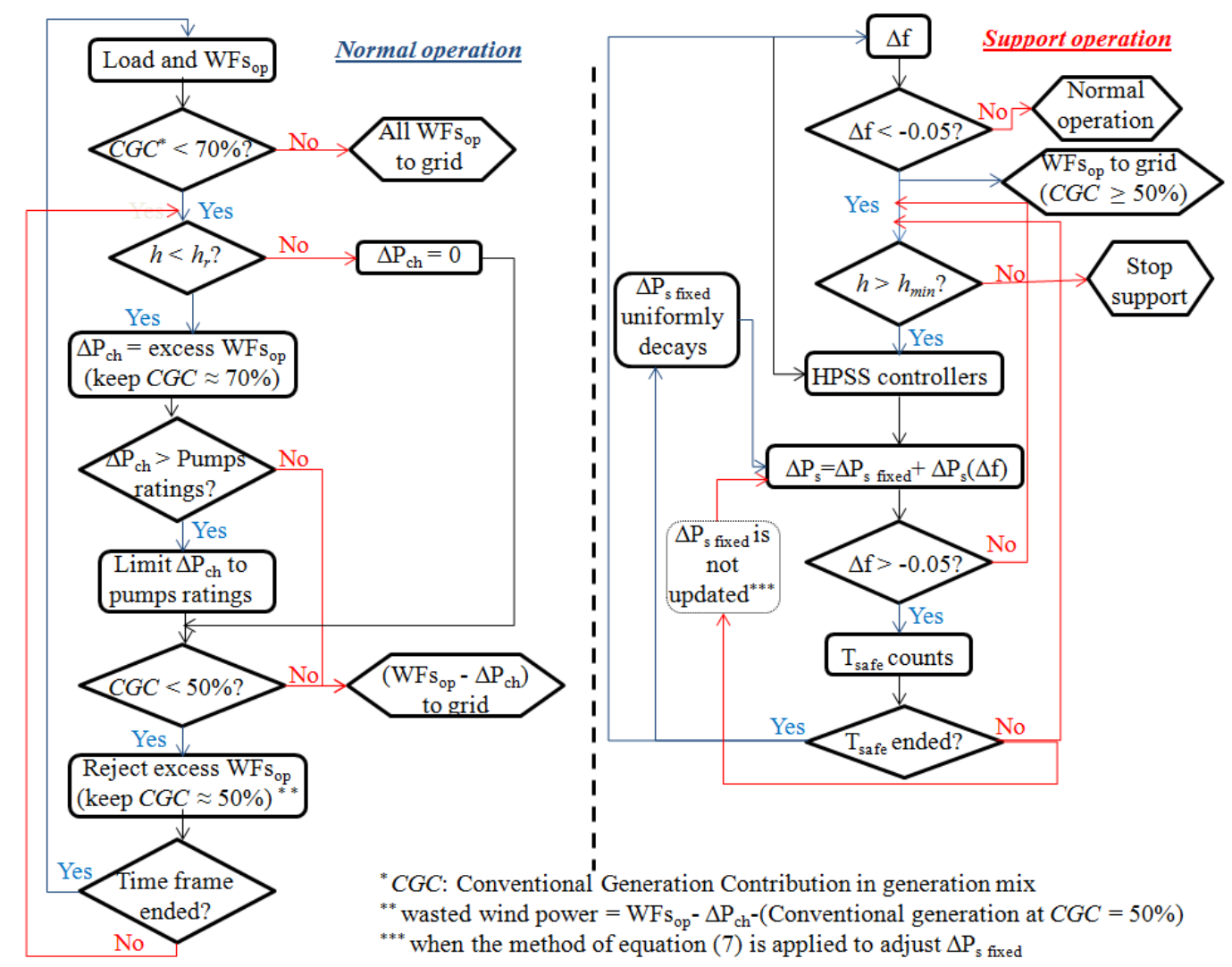

Fig. 4 Normal and Support operation modes flowcharts

\section{Frequency support analysis}

\subsection{Case studies}

Two case studies are investigated to examine the impact of HPSS integration and proposed algorithms. The Base case represents the test system without the integration of WFs and HPSS. The conventional generation is represented by two aggregate generators (one for each technology). Double reheat turbine for steam generator G1, and gas turbine for thermal generator G2. The standard models of gas turbine in [28], and double reheat turbine in [29] are applied. The droops and inertias of G1 and G2 are included in Figure 5, meanwhile figures of their governors are found in the Appendix. Frequency dynamics are simulated by a single block including the system aggregate inertia $(\mathrm{H})$ based on the concepts presented in $[25,30]$.

First case study integrates the considered seven WFs, and the corresponding conventional capacity is replaced, meanwhile HPSS is not integrated. The WSs records in each location through the simulation interval are shown in Figure 6.

Second case study integrates the designed HPSS, and operates it using the offered algorithm, and examines the influence of $\Delta \mathrm{P}_{\text {s-fixed }}$ on frequency response. The authors preferred to focus on the impact of high and low thresholds for $\Delta \mathrm{P}_{\text {s-fixed, }}$, therefore $\Delta \mathrm{P}_{\text {s-fixed }}$ is not determined using (7), to avoid the dependence on RoCoF. Alternatively, two different values 
for $\mathrm{R}_{\mathrm{WFs}}$ are applied, namely, $6 \%$ and $10 \%$ such that $\Delta \mathrm{P}_{\mathrm{s} \text {-fixed }}$ is predetermined using (6). In words, $\Delta \mathrm{P}_{\text {s-fixed }}=0.37$ and 0.62 p.u. in Second case studies $A$ and $B$ respectively. The performed case studies are also illustrated in Figure 6. Table 5 includes major data about HPSS turbine, generator, governor, and the dynamic load model. It is of note that, $\mathrm{H}$ is updated in each case study using (8). The capacity and inertia of an aggregate plant ' $i$ ' are $\mathrm{S}_{i}$ and $\mathrm{H}_{i}$ respectively, while ' $I$ ' is the number of installed power plants (e.g., in Case 2, $I=3$ including; steam, and gas aggregate plants, and HPSS).

$H=\frac{\sum_{i=1}^{l} H_{i} \cdot S_{i}}{\text { Conventional cpacity before WFs integration }}$

Table 5 Integrated hydro generation plant and dynamic load specifications

\begin{tabular}{|c|c|}
\hline No. of generators & 1 \\
\hline Rated output & $300 \mathrm{MW}$ \\
\hline Inertia $(\mathrm{H})$ & $4 \mathrm{~s}$ \\
\hline Droop $(\mathrm{R})$ & $5 \%$ \\
\hline $\mathrm{G}_{\mathrm{o}}$ and $\mathrm{G}_{\text {no load }}$ (Turbine thresholds) & 0.94 and $0.06 \mathrm{p} . \mathrm{u}$. \\
\hline $\mathrm{T}_{\mathrm{w}}$ (water starting time) & $1.9 \mathrm{~s}$ \\
\hline $\mathrm{W}_{\mathrm{o}}$ (Rotating mass loads parameter) & $120 \mathrm{~Hz} / \mathrm{MW}$ \\
\hline $\mathrm{D}_{\mathrm{l}}$ (Frequency dependent loads parameter) & $1 / 240 \mathrm{MW} / \mathrm{Hz}$ \\
\hline
\end{tabular}

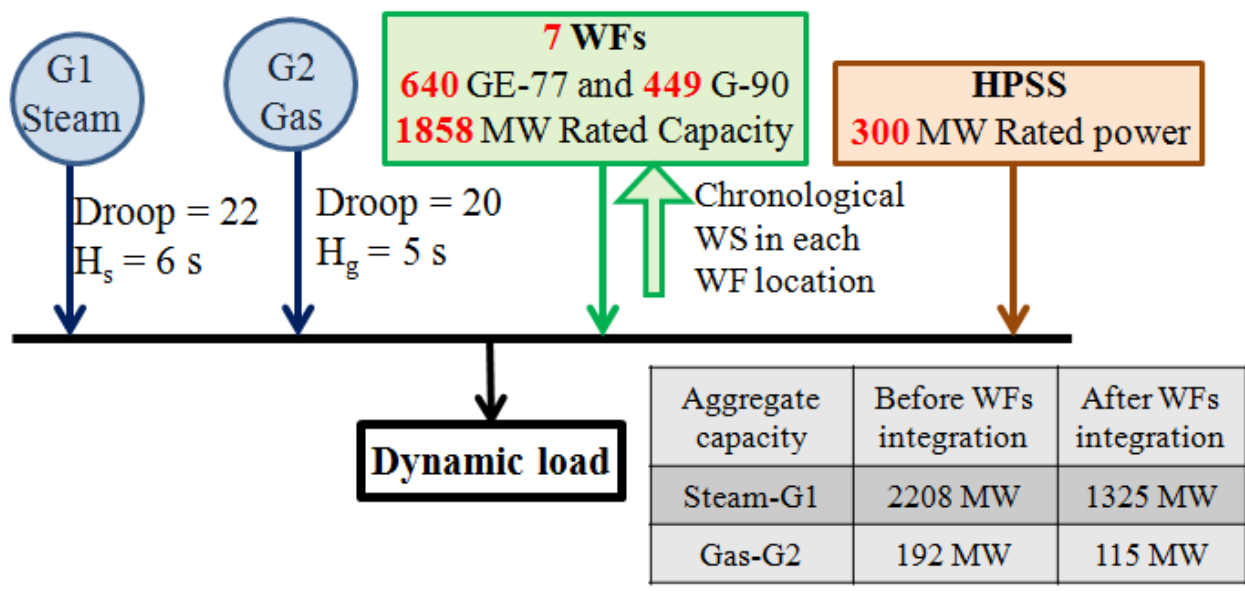

\begin{tabular}{|c|c|}
\hline Cases & Description \\
\hline Base & Conventional generation $\underline{\text { before WFs integration, No WFs, No HPSS }}$ \\
\hline Case 1 & Conventional generation $\underline{\text { after WFs integration, with WFs, No HPSS }}$ \\
\hline Case $2 \mathrm{~A}$ & Conventional generation $\underline{\text { after }}$ WFs integration, with WFs, HPSS $\left(\Delta \mathrm{P}_{\text {s-fixed }}=0.37\right)$ \\
\hline Case 2B & Conventional generation $\underline{\text { after }}$ WFs integration, with WFs, HPSS $\left(\Delta \mathrm{P}_{\text {s-fixed }}=0.62\right)$ \\
\hline
\end{tabular}

\begin{tabular}{|c|c|}
\hline Events & Description \\
\hline Event 1 & Sudden increase in load from 1273 to $1400 \mathrm{MW}$ at $\mathrm{t}=20750 \mathrm{~s}$ \\
\hline Event 2 & Sudden loss of $128 \mathrm{MW}$ steam unit at $\mathrm{t}=20840 \mathrm{~s}$ \\
\hline
\end{tabular}

Fig. 5 Test system single line diagram illustrating the implemented case studies 


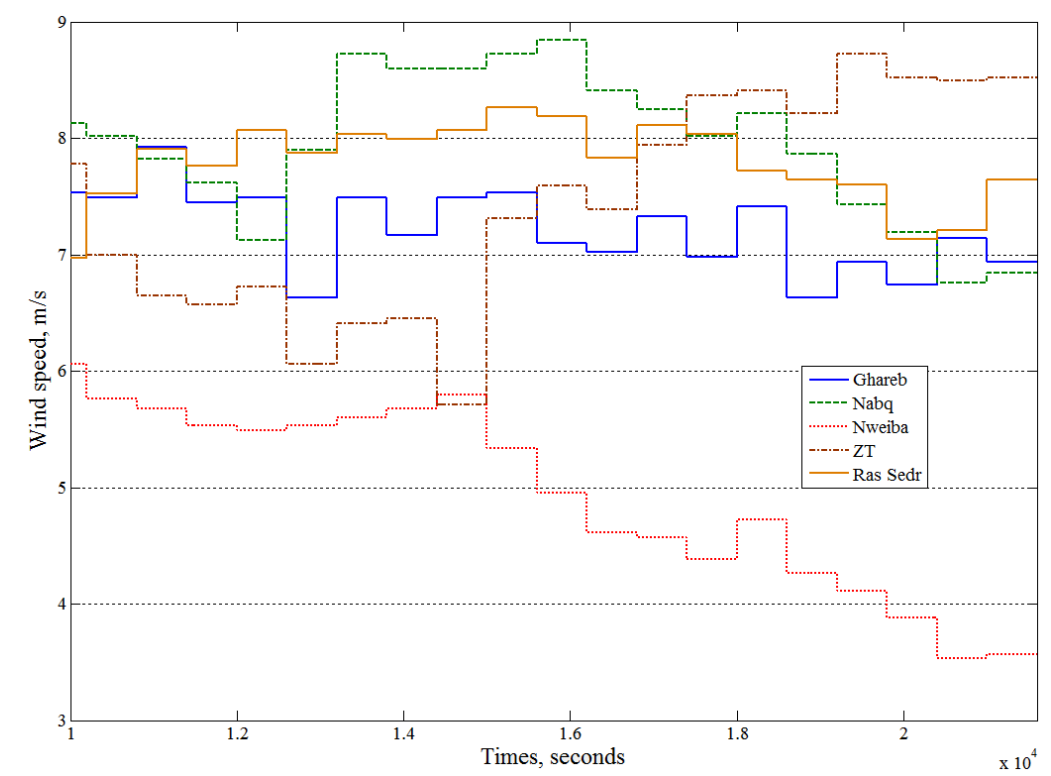

Fig. 6 WSs values during certain simulation span in selected five locations

In this paper each WF is composed from two types of WTs (G-90 and GE-77) and each type contributes by a given number of WTs as explained earlier in Subsection 2.1. In dynamic simulation, the look-up tables (WS vs. Output power) for both types are used to obtain WT output according to the instantaneous WS. The wake and tower shadowing effects are ignored, so that the instantaneous WS across the whole WF terrain is similar. Therefore, WF aggregated output at certain time instant $(t)$ is calculated using (9), where Output power is $_{i}$ is obtained from the look-up table of the corresponding WT type. $\mathrm{WFs}_{\mathrm{op}}$ is always reduced by $10 \%$ as an acknowledgment for wake effects, and losses of power electronics devices and transmission.

$$
W F_{\text {output }}(t)=0.9 \cdot\left(\sum_{i=1}^{\text {No. of WTs types inside WF }}(\text { Output power } i(W S(t)) \cdot \text { No. of WTs from type } i)\right)(9)
$$

All cases are executed within certain time interval, namely six continuous hours in certain day $(21600 \mathrm{~s})$. The selection of certain quarter day is based on the production of the two types of WTs, and the chronological data of WS. In particular, the WS which makes the WT produces $60 \%$ from its rated power is obtained from WT power curve (i.e., 8.79 and $7.88 \mathrm{~m} / \mathrm{s}$ for G-90 and GE-77 respectively). An average for both WSs is calculated, and the day which records the highest probability of occurrence for these two values in the seven locations is selected. The last six hours in $73^{\text {rd }}$ day $\left(15^{\text {th }}\right.$ March) in the available year of data fulfil this criterion; hence the load and WS data of these hours is implemented.

After $20750 \mathrm{~s}$ the system suffers a $10 \%$ sudden increase in load demand, and $90 \mathrm{~s}$ later; a forced outage for a single generator in Auon Mousa plant occurs (i.e., plant is composed from 5 typical units, so that 1 generator is equivalent to $128 \mathrm{MW}$ ). All the case studies are subjected to these two events. To emphasis the impact of WFs and HPSS integration; the load control 
signal fed to conventional generators is delayed by $20 \mathrm{~s}$ after the first event. This signal is responsible for recovering the frequency to its nominal value after load changes (i.e., some literatures call it secondary response or load-generation control). In words, frequency recovery depends only on system inertia and generators' primary response within $20 \mathrm{~s}$ after each event is initiated. Likewise, steam generation outage is reported to conventional generators' controllers after $20 \mathrm{~s}$ from its occurrence. It is of note that, WS changes every 10 minutes according to the available chronological data, hence WSs in all locations are fixed during the two events. Illustrative tables for all cases studies and the accompanying events are included in Figure 6.

\subsection{Results and discussion}

The frequency responses of all case studies are compared during the two implied events. To emphasis the differences between the frequency responses; four metrics are calculated: 1) maximum frequency drop $\left.\left(\Delta \mathrm{f}_{\mathrm{m}}\right), 2\right)$ RMS and average values of frequency deviations within 1 minute from event initiation $\left.\left(\Delta \mathrm{f}_{\mathrm{RMS}}, \Delta \mathrm{f}_{\text {avg }}\right), 3\right) \Delta \mathrm{f}$ after $10 \mathrm{~s}$ from event initiation $\left(\Delta \mathrm{f}_{10 \mathrm{~s}}\right)$ and 4$)$ time required to reach safe margin for the first time after event initiation $\left(\mathrm{T}_{S M}\right)$. Figures 7 and 8 , besides Table 6 show the major outcomes. The time axis of all figures is shifted to focus only on the interval that includes the two frequency events.

The first note is the improved results of Event 2 compared to Event 1 in all cases. This returns to the higher deficit between generation and demand in Event 1 (i.e., $127 \mathrm{MW}$ ). Keep in mind that Event 2 is caused by $128 \mathrm{MW}$ sudden loss in conventional capacity. However, the lost unit is not fully loaded at the event start; hence the miss match is only $70 \mathrm{MW}$ as revealed by Figure 9. The integration of HPSS reduces $\Delta \mathrm{f}_{\mathrm{m}}$ but it doesn't completely eliminate the impact of WFs replacement for conventional plants. In particular, $\Delta \mathrm{f}_{\mathrm{m}}$ in Cases $2 A$ and $2 B$ are always worse compared to Base case. The system inertia is reduced since the WTs are considered to be inertia-less from the point of view of power system [7], and they replaced $40 \%$ from Base Case conventional generation capacity. As an illustration, WT is a rotating machine, and has its own inertia that could be modelled by a single or double mass model. However, the power electronics converters between WT and power system decouple the WT from system frequency variations, so that WT is not able to provide inertial response during frequency drops (i.e., WT does not extract any kinetic energy to provide inertial response in case of frequency drops). Literature proposed modified operation algorithms to make the WT provides virtual inertial response, and primary support. Such algorithms force the WT to deviate from MPT during normal operation, hence some energy is wasted [6,31]. Theoretically, WFs have no influence on system inertia, but the retirement of conventional 
units without compensating their inertial and primary responses reduces system inertia, and robustness against frequency deviations.

Case 1 recorded the worst results, meanwhile Case $2 A$ has an overall better results. For example, $\Delta \mathrm{f}_{\text {avg }}, \Delta \mathrm{f}_{10 \mathrm{~s}}$ and $\Delta \mathrm{f}_{\mathrm{RMS}}$ in Case $2 A$ are improved or at least not changed compared to Base and Case 1 due to the integration of HPSS. For example, $\Delta \mathrm{f}_{\mathrm{RMS}}$ is lower in Case $2 \mathrm{~A}$ compared to Case 1. Also, in Event $1, \Delta \mathrm{f}_{\mathrm{RMS}}$ is obviously mitigated, such that it is less than Base case, and $\Delta \mathrm{f}_{10 \mathrm{~s}}$ in Event 2 is alleviated with respect to Base case. A unique result is found in Event 2 (Case $2 B$ ), where $\Delta \mathrm{f}_{\text {avg }}$ has a positive value. As an interpretation, lower $\Delta \mathrm{f}_{\mathrm{m}}$ and higher $\Delta \mathrm{P}_{\text {s-fixed }}$ caused this switch in $\Delta \mathrm{f}_{\text {avg. }}$ Generally, the impact of positive frequency deviations is less dangerous on power systems and its treatment is easier, as it does not require extra energy sources.

$\mathrm{T}_{S M}$ in Cases $2 A$ and $2 B$ are dramatically shortened compared to Base case, as a result to the extra injected active power by HPSS. On the other hand, Case $2 B$, higher $\Delta \mathrm{P}_{\text {s-fixed }}(186$ $\mathrm{MW}$ ), caused undesirable frequency overshoots. Consequently, $\Delta \mathrm{f}_{\mathrm{RMS}}$ increases, so that Case $2 B$ has the highest value among all cases, except Event 1 in Case 1 . Conversely, high $\Delta \mathrm{P}_{\text {s-fixed }}$ has solidly improved $\Delta \mathrm{f}_{\text {avg }}$, especially in Event 1 . It is expected, $\mathrm{T}_{\text {safe }}$ and $\mathrm{T}_{\text {safe2 }}$ are the main controllable factors to suppress the positive overshoots as revealed by the attitude of steam generation in Figure 9.

The HPSS output is depicted in Figure 10 to analyze the performance of HPSS generation during the support phase. HPSS output is zero all the time before the first event. As soon as $\Delta \mathrm{f}$ violates the safe margin, output power increases rapidly following the governor response, and the new reference power, namely, $\Delta \mathrm{P}_{\text {s-fixed. }}$ The relatively short time constant of water and gate motion of HPSS contributes in this fast response. In addition HPSS output is simulated taking into consideration the possibility of installing more than one generator (typical parallel units). Thus, the model provides the output in per unit referred to the 'aggregate capacity'. Therefore, the overall response increased in a relatively high rate, because it is the aggregation of parallel responses of more than one unit (e.g., two generators as discussed earlier in Section 2).

After $\mathrm{T}_{\text {safe }}$ ends, $\Delta \mathrm{P}_{\mathrm{s} \text {-fixed }}$ signal decays gradually, and the output almost follows the same trend. The impact of this uniform decay is clear on $\Delta \mathrm{f}$, so that it takes longer time until it stabilizes at almost zero value. The governor response also participates in smoothing the retreat of HPSS from generation mix after the frequency drop is almost cleared. It is of note that, in Case $2 B$-Event $1, \Delta \mathrm{P}_{\text {s-fixed }}$ decay process is interrupted, thus $\mathrm{T}_{\text {safe }}$ is reset as highlighted in Figure 10. As an illustration, when the high $\Delta \mathrm{P}_{\mathrm{s}-\text { fixed }}$ is gradually reduced, the generation-load 
balance is disturbed by a margin that caused the frequency to drop again below the safe margin. Conversely, in Case $2 A, \mathrm{~T}_{\text {safe }}$ is reset only in Event 2, but with less severity, and it takes shorter time to recover $\Delta \mathrm{f}$ to safe region (i.e., lower $\Delta \mathrm{P}_{\text {s-fixed }}$ mitigates the disturbance in generation-load balance during $\Delta \mathrm{P}_{\text {s-fixed }}$ withdraw). Steam generation shown in Figure 9 is aligned with the previous analysis. The critical stage is the switching from major support stage (i.e., when $\mathrm{T}_{\text {safe }}$ is counting) to uniform retreat of HPSS ( $\Delta \mathrm{P}_{\mathrm{s}-\text { fixed }}$ regular decay). Keep in mind that, $T_{\text {safe }}$ and $T_{\text {safe2 }}$ are reset when $\Delta f$ drops below the safe margin.

Finally, the variations of water level inside the reservoir and the corresponding flow rates in and out are observed in Figure 11. In the early stage of simulation span (i.e., the selected six hours), water reservoir is filled with water starting from $h_{\min }$, such that it reached $h_{r}$ within 107 minutes. The reservoir is assumed to be closed, thus $h$ is not affected by possible rains or vaporization. The stored wind energy within simulation span is $180 \mathrm{MWh}$, which is a promising value, corresponding to the average energy price in Egypt $(0.15 € / \mathrm{kWh})$. It is also worth mentioning that the out coming flow rate is completely aligned with the HPSS output depicted in Figure 10. For example, at higher $\Delta \mathrm{P}_{\text {s-fixed }}$ in Case $2 B, Q_{\text {out }}$ increases, however $Q_{\text {out }}$ does not rise with the rate by which $\Delta \mathrm{P}_{\text {s-fixed }}$ rises. In particular, $Q_{\text {out }}$ is affected by other factors, including the water discharging equation, but still the general trend perfectly matching that of HPSS output. The $Q_{\text {out }}$ is fast rate of increase is expected due to the free fall of water. The smooth initiation of pumping is clear in Figure 11, where the withhold power from $\mathrm{WFs}_{\mathrm{op}}$ to run the pumps increases gradually, and correspondingly $Q_{i n}$ increases. However, deep analysis of pumps' detailed transients is not mandatory to achieve the paper aims, especially; as it does not affect the HPSS supporting role during frequency events (i.e., pumps are utilized only during Normal operation). The No-pumping duration, that is applied to secure frequency stability after the system gets over the frequency deviation, is also highlighted in Figure 11.

Table 6 Values of frequency analysis metrics

\begin{tabular}{|c|c|c|c|c|c|c|}
\hline Parameter & \multicolumn{2}{|c|}{$\Delta \mathrm{f}_{\mathrm{m}}, \mathrm{mHz}$} & \multicolumn{2}{c|}{$\Delta \mathrm{f}_{10 \mathrm{~s}}, \mathrm{mHz}$} & \multicolumn{2}{c|}{$\mathrm{T}_{\mathrm{SM}}, \mathrm{s}$} \\
\hline Case study & Event 1 & Event 2 & Event 1 & Event 2 & Event 1 & Event 2 \\
\hline Base & -192 & -126 & -75 & -57 & 22 & 13.5 \\
\hline Case 1 & -318 & -207 & -125 & -97 & 23 & 22.5 \\
\hline Case 2A & -273 & -174 & -79 & -23 & 4 & 3 \\
\hline Case 2B & -279 & -178 & 144 & 130 & 3 & 3 \\
\hline
\end{tabular}



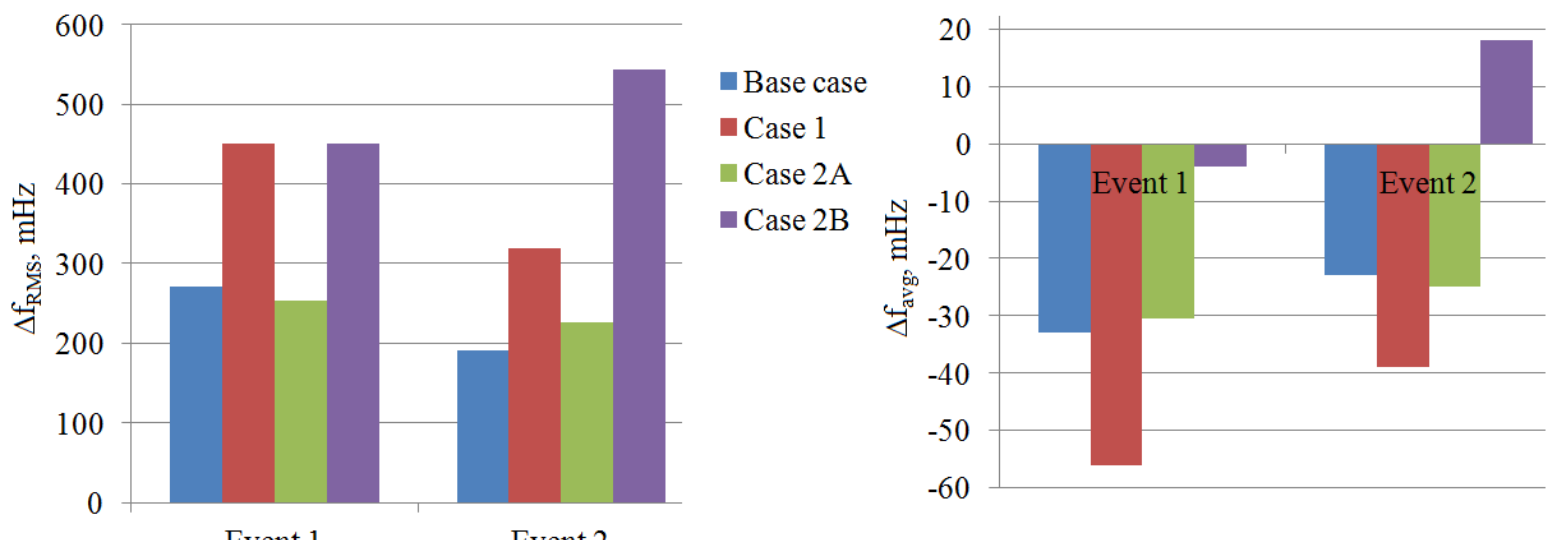

Event 1

Fig. 7 Frequency analysis parameters values

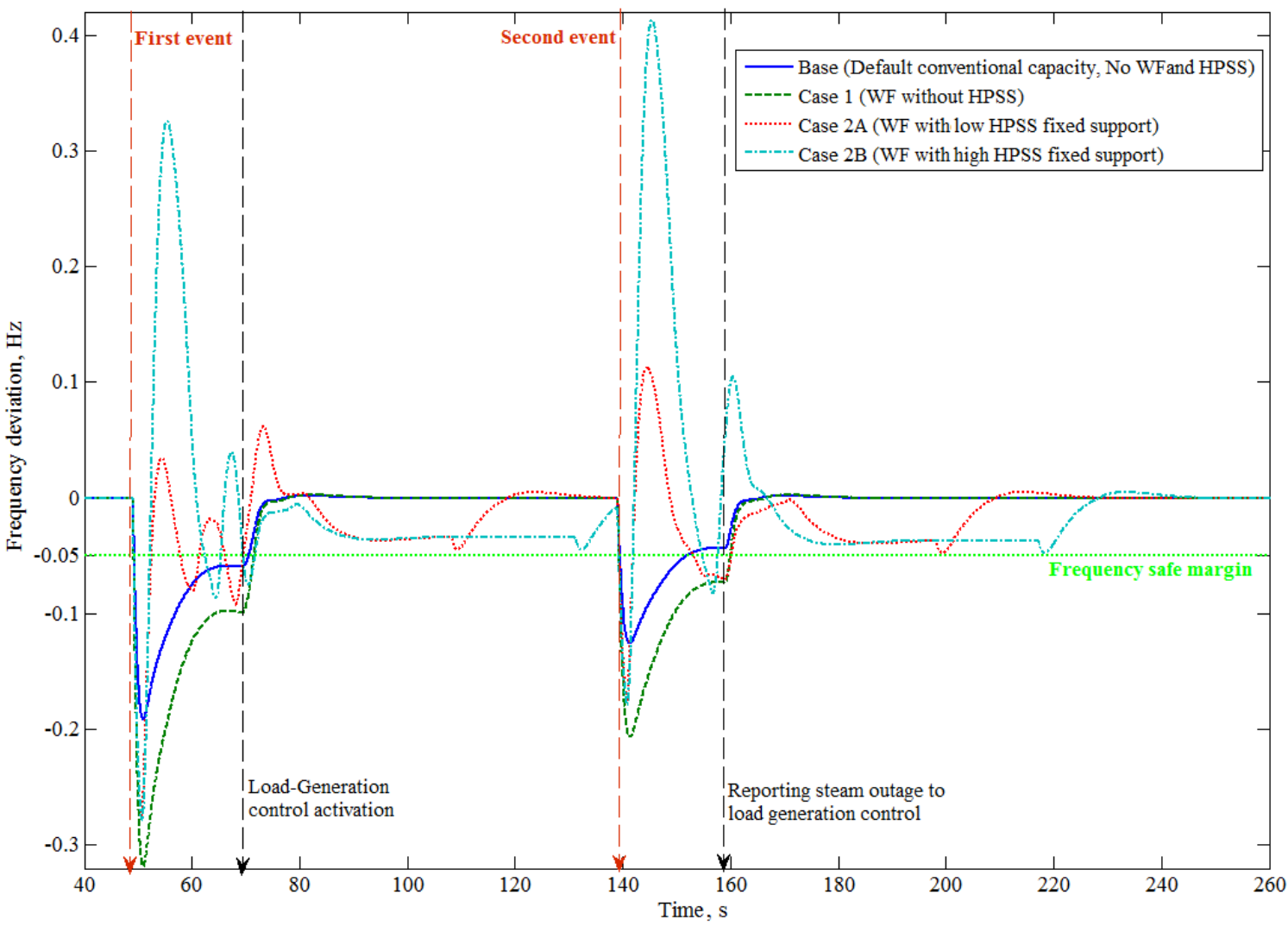

Fig. 8 Frequency responses during both events for all case studies 


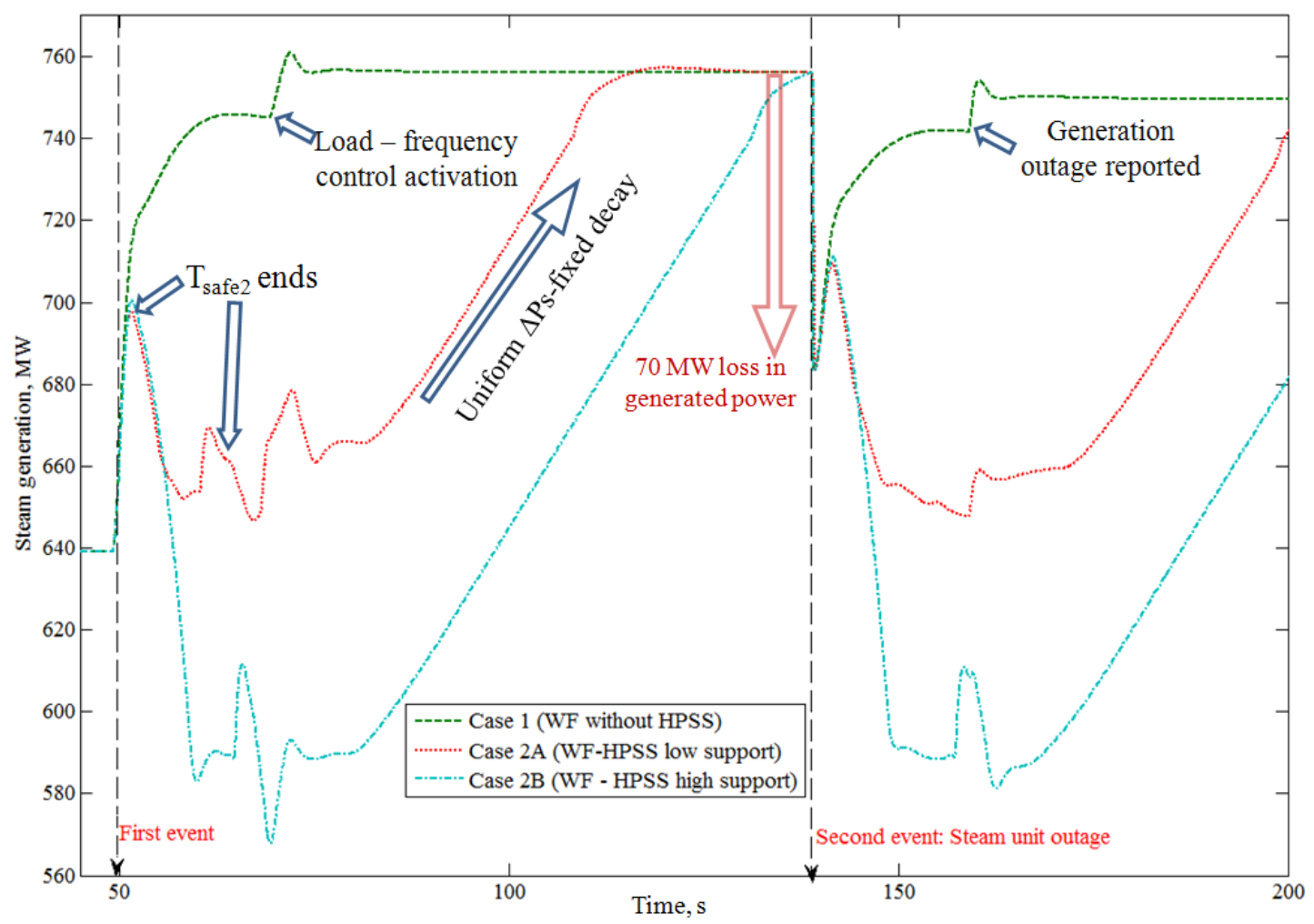

Fig. 9 Steam generation during the two events

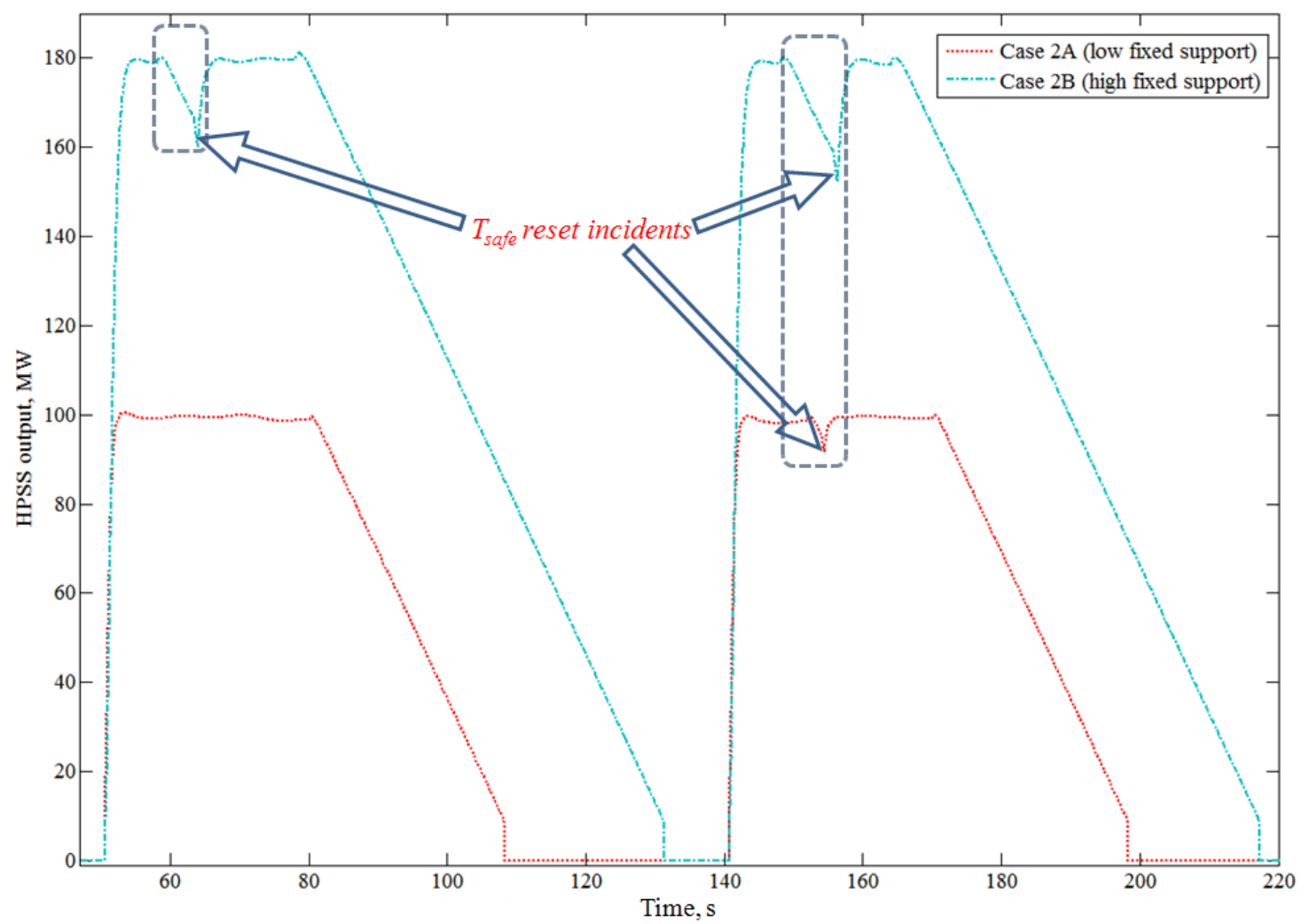

Fig. 10 HPSS output during implied events 


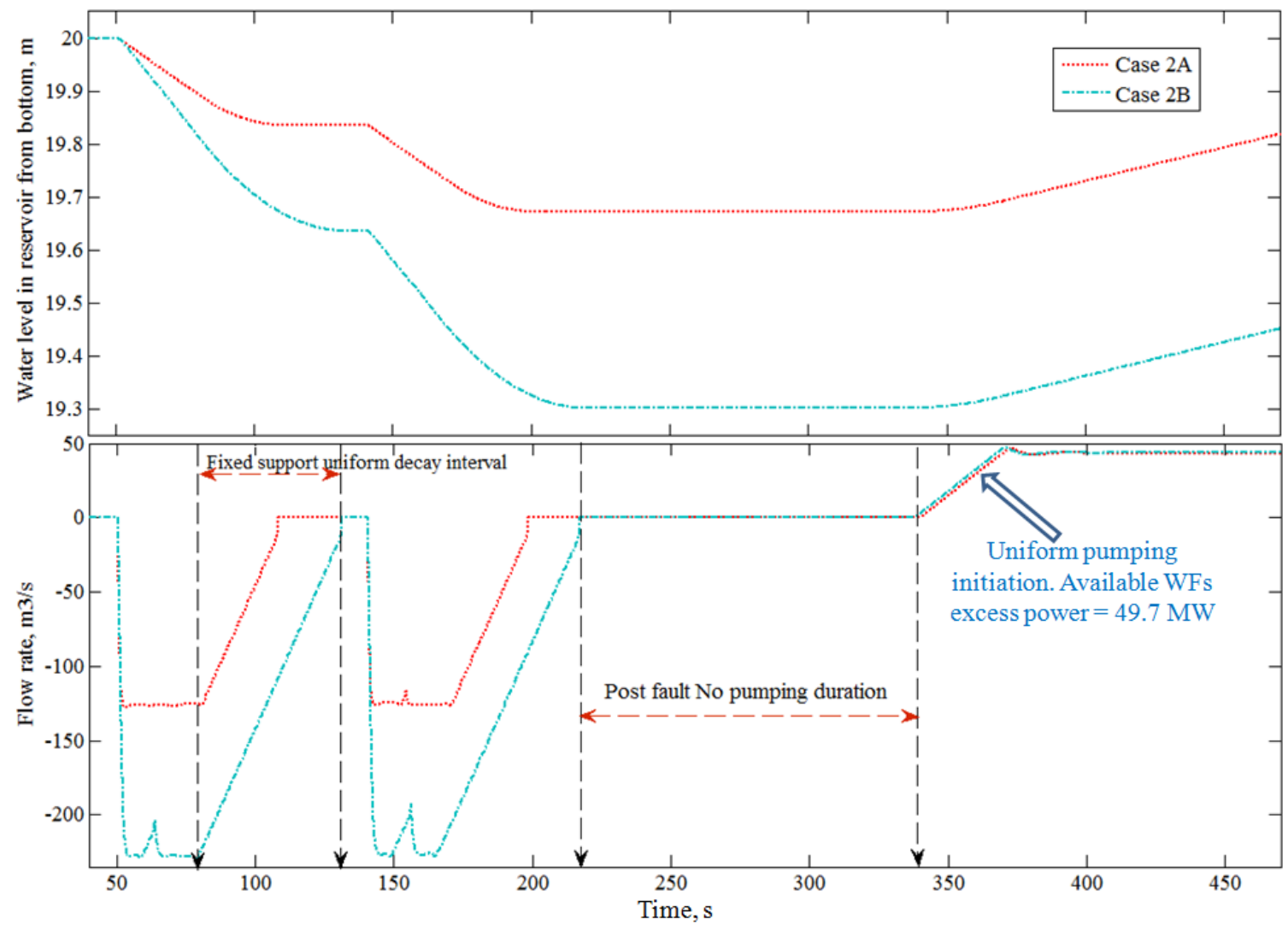

Fig. 11 Water level inside the water reservoir and flow rate variations of HPSS

\section{Conclusions}

This paper presents an algorithm to utilize HPSS, which stores excess wind energy rejected by power system, and provides power support during frequency drops through a detailed and precise operation algorithm. Offered algorithm acknowledges several dynamic and static factors including the reference power, and frequency deviation signals fed to HPSS. In addition, it controls the common signals between conventional plants, and HPSS to guarantee a smooth frequency recovery.

Specific wind farms replace high ratio from conventional generation, and then HPSS power rating and energy capacity are estimated in the light of the expected chronological power deficits. The impact of installing HPSS on frequency response recovery is examined through two comprehensive case studies. Results revealed the feasibility of the proposed algorithm, where HPSS integration compensates the reduction of system inertia after WFs integration, and saves considerable amounts of wind energy. The evaluated frequency metrics insure the positive influence of the supportive response provided by the HPSS, especially in frequency nadir and time to reach safe region. The attained improvements are comparable to those achieved by support algorithms that are integrated into wind turbines. But the predetermined and guaranteed reaction of HPSS is a major merit, besides the mitigation of 
wasted wind energy. However, the tuning of fixed support power value is crucial, such that a compromise is needed between fast frequency drop elimination, and alleviating possible postevent oscillations or positive overshoots. In future, further investigations are executed to suppress positive overshoots, through linking the magnitude of fixed support power to the instantaneous value of RoCoF. In addition, available budget, and geographical nature are considered, and their influence on increasing the rating and capacity of HPSS to extend its role, and minimize the rejected wind energy.

\section{Appendix}

Table A.1 Values of steam turbine implemented parameters

\begin{tabular}{|c|c|}
\hline \multicolumn{2}{|c|}{ Steam turbine double reheat } \\
\hline Parameter & value \\
\hline $\mathrm{T}_{\mathrm{ch}}$ & $0.25 \mathrm{~s}$ \\
\hline $\mathrm{T}_{\mathrm{co}}$ & $0.4 \mathrm{~s}$ \\
\hline $\mathrm{T}_{\mathrm{rh} 1}$ & $7.5 \mathrm{~s}$ \\
\hline $\mathrm{T}_{\mathrm{rh} 2}$ & $7.5 \mathrm{~s}$ \\
\hline $\mathrm{F}_{\mathrm{hp}}$ & $0.22 \mathrm{p.u}$. \\
\hline $\mathrm{F}_{\mathrm{ip}}$ & $0.3 \mathrm{p} . \mathrm{u}$. \\
\hline $\mathrm{F}_{\mathrm{vhp}}$ & $0.22 \mathrm{p} . \mathrm{u}$. \\
\hline $\mathrm{F}_{\mathrm{lp}}$ & $0.26 \mathrm{p} . \mathrm{u}$. \\
\hline
\end{tabular}

Table A.2 Implemented governors' parameters values

\begin{tabular}{|c|c|c|c|}
\hline \multicolumn{2}{|c|}{ Steam governor } & \multicolumn{2}{|c|}{ Hydro governor } \\
\hline Parameter & value & Parameter & Value \\
\hline $\mathrm{T}_{1}$ & $2.8 \mathrm{~s}$ & $\partial$ & $0.2 \mathrm{~s}$ \\
\hline $\mathrm{T}_{2}$ & $5 \mathrm{~s}$ & $\mathrm{~T}_{\mathrm{g}}$ & $0.2 \mathrm{~s}$ \\
\hline $\mathrm{T}_{3}$ & $0.15 \mathrm{~s}$ & $\mathrm{~T}_{\mathrm{p}}$ & $0.045 \mathrm{~s}$ \\
\hline \multicolumn{2}{|c|}{ Valve rate limits } & \multicolumn{2}{|c|}{ Gate rate limits } \\
\hline Increasing & 0.2 p.u. & Increasing & 0.2 p.u. \\
\hline Decreasing & -1 p.u. & Decreasing & -0.2 p.u. \\
\hline \multicolumn{2}{|c|}{ Valve opening limits } & \multicolumn{2}{|c|}{ Gate opening limits } \\
\hline Max & 1p.u. & Max & 1 p.u. \\
\hline Min & 0 & Min & 0 \\
\hline
\end{tabular}

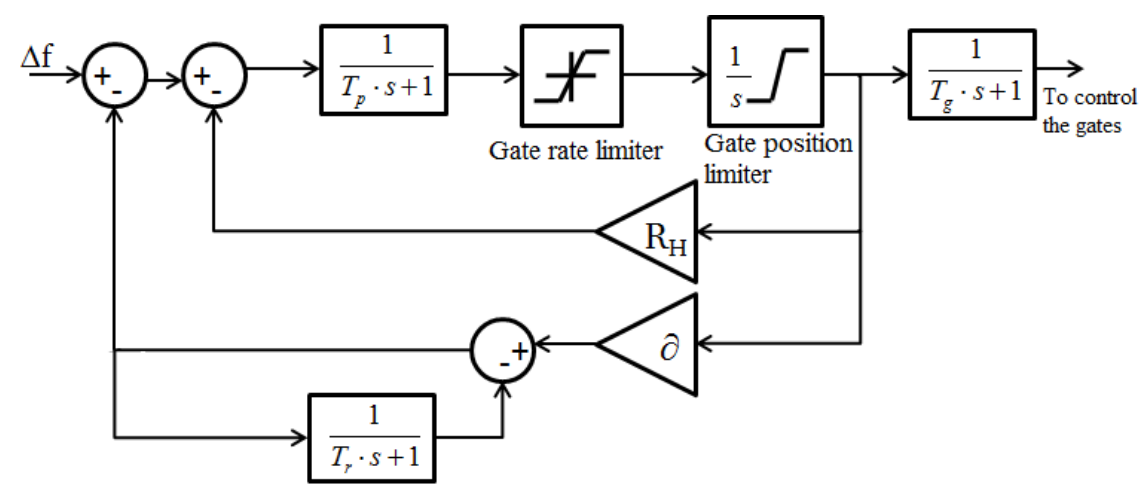

Fig. A.1 Hydro generator governor [25] 


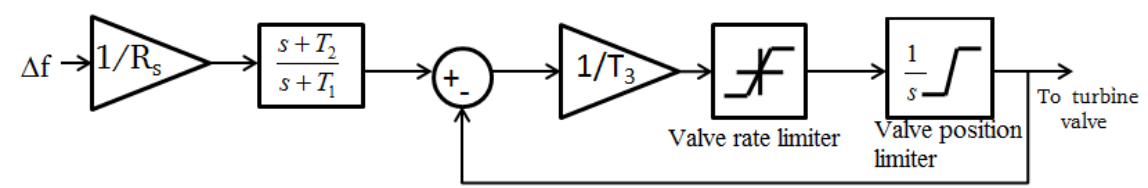

Fig. A.2 Steam generator governor [29]

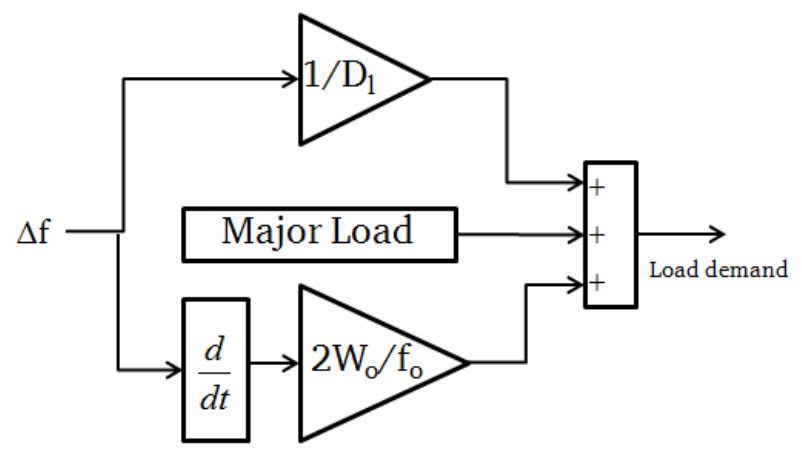

Fig. A.3 Lumped load model [30]

Hint: for nomenclature please refer to [26,25,29,30]

\section{References}

[1] H. Holttinen, et al., "Currents of changes," IEEE Power and Energy Magazine, vol. 9, no. 6, pp. 47-59, 2011.

[2] T. Ackermann, Wind Power in Power Systems. John Wiley \& Sons Ltd, 2005.

[3] B. Fox, L. Bryans, D. Flynn, N. Jenckins, and D. Milborrow, Wind Power Integration. IET Power and Energy Series 50, 2007.

[4] Z. J. Meng, "An improved equivalent wind method for the aggregation of DFIG wind turbines," in IEEE International Conference on Power System Technology (POWERCON), China, 2010.

[5] B. G. Rawn, M. Gibescu, and W. L. Kling, "Kinetic Energy from Distributed Wind Farms: Technical Potential and Implications," in IEEE Innovative Smart Grid Technologies Conference Europe, 2010.

[6] A. B. T. Attya and T. Hartkopf, "Control and quantification of kinetic energy released by wind farms during power system frequency drops," IET Renewable Power Generation, vol. 7, no. 3, 2013.

[7] L. Ruttledge, N. W. Miller, J. O'Sullivan, and D. Flynn, "Frequency Response of Power Systems with Variable Speed Wind Turbines," IEEE transactions on Sustainable Energy, vol. 3, no. 4, pp. 683-691, 2012.

[8] C.-C. Le-Ren and Y. Yao-Ching, "Strategies for Operating Wind Power in a Similar Manner of Conventional Power Plant," IEEE transactions on energy conversion, vol. 24, no. 4, pp. 926-934, 2009.

[9] J. A. Martinez, "Modeling and characterization of energy storage devices," in IEEE Power and Energy Society General Meeting, San Diego, CA, 2011.

[10] D. Al. Katsaprakakisa, D. G. Christakisa, A. Zervosb, D. Papantonisb, and S. Voutsinasb, "Pumped storage systems introduction in isolated power," Elsevier Journal of Renewable Energy, no. 33, p. 467490, 2008.

[11] Kazunori Iwabuchil, et al., Advanced Governor Controller for Pumped-Storage Power Plant and its Simulation Tool, in SICE-ICASE International Joint Conference, Busan, Korea, 2006.

[12] M. Ceraolo, "New dynamical models of lead-acid batteries," IEEE Transactions on Power Systems, vol. 15, no. 4, pp. 1184-1190, 2000.

[13] J. S. Anagnostopoulo and D. E. Papantonis, "Simulation and size optimization of a pumped-storage power plant for the recovery of wind-farms rejected energy," Elsevier journal of Renewable Energy, no. 33, p. 1685-1694, 2008.

[14] A. B. Attya, H. Ali, and T. Hartkopf, "Frequency drops mitigation at high wind energy penetration by hydro-pumped storage - Capacity sizing," in IEEE 17th Mediterranean Electrotechnical Conference, Beirut, 2014.

[15] Egyptian ministry of electrcivty and enery, "Annual energy and power generation report," 2010.

[16] R. Castro and L. Ferreira, "A comparison between chronological and probabilistic method to estimate 
wind power capacity credit," IEEE Trans. on Power Systems, vol. 16, no. 4, pp. 904-909, 2001.

[17] V. Gevorgian, Y. Zhang, and E. Ela, "Investigating the Impacts of Wind Generation Participation in Interconnection Frequency Response," IEEE transactions on Sustainable Energy, vol. early access, 2014.

[18] N. Miller, W. Price, and J. Sanchez-Gasca, "Dynamic modeling of GE 1.5 and 3.6 MW wind turbine generators," in Technical report, GE company, 2003.

[19] Gameza company, "Brochure of Wind Turbine: G-90-2.0 MW," 2011.

[20] N. G. Mortensen and U. S. Said, "Wind Atlas for Egypt," 2009.

[21] J. Chaurette, Pump system analysis and sizing. Fluide Design Inc., 2002.

[22] F. Avellan, "Storage pumps and reversible pump turbines scientific and technical challenges," in Renewables grid initiative, Montreaux, 2011.

[23] Voith company, Pumps Tailormade solutions for water applications, [online: voith.com/de/12_06_Pumpenbroschuere.pdf]

[24] A. R. Bergen and V. Vittal, Power System Analysis, Second Edition. Prentice Hall, 2000.

[25] P. Kundur, Power System Stability and Control. 1994: McGraw-Hill Inc., New York.

[26] I. Kamwa, D. Lefebvre, and L. Loud, "Small signal analysis of hydro-turbine governors in large interconnected power plants," in IEEE Power Engineering Society Winter Meeting, Varennes, Canada, 2002.

[27] UCTE, Appendix 1 - Load-Frequency Control and Performance. The Union of the coordination of the transmission of electricity , 2002.

[28] H. Emam Shalan, M. A. Moustafa Hassan, and A. B. G. Bahgat, "Parameter estimation and dynamic simulation of gas turbine model in combined cycle power plants based on actual operational data," Journal of American Science, vol. 7, no. 5, pp. 303-310, 2011.

[29] IEEE report, "Dynamic models for steam and hydro turbines in power system studies," IEEE Transactions on Power Apparatus System, vol. 92, no. 6, pp. 1904-1915, 1973.

[30] G. Andersson, Lecture notes: Dynamics and control of eletrical power systems. Zurich: ETH Zurich, 2011.

[31] M. F. M. Arani and E. F. El-Saadany, "Implementing virtual inertia in DFIG-based wind power generation," IEEE Transactions on Power Systems, vol. 28, no. 2, pp. 1373-1384, 2012. 